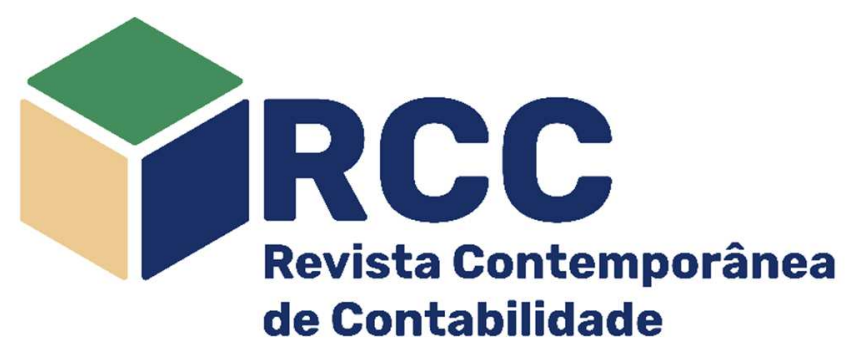

\title{
Gerenciamento por decisões operacionais: alternativa para evitar reportar prejuízos
}

\author{
Real earnings management: an alternative to avoid reporting losses \\ Gestión de resultados reales: una alternativa para evitar reportar pérdidas
}

\author{
Nevison Amorim Pereira \\ Doutor em Ciências Contábeis (UFU) \\ Administrador na Universidade Federal de Uberlândia, \\ Uberlândia/MG, Brasil \\ nevison@ufu.br \\ https://orcid.org/0000-0001-7168-0267 (D)
}

\author{
Marcelo Tavares \\ Doutor em Genética e Melhoramento de Plantas (ESALQ/USP) \\ Professor do Programa de Pós-Graduação em \\ Ciências Contábeis (UFU), Uberlândia/MG, Brasil \\ mtavares@ufu.br \\ https://orcid.org/0000-0003-3008-3460 (1)
}

Endereço do contato principal para correspondência* Av. João Naves de Ávila, 2121, Bloco 3P, sala 203, Santa Mônica, CEP: 38.400-902, Uberlândia/MG, Brasil

\begin{abstract}
Resumo
O objetivo desse trabalho foi verificar se as empresas brasileiras listadas na Brasil, Bolsa, Balcão $[\mathrm{B}]^{3}$ utilizaram-se do gerenciamento de resultados por atividades reais para evitar reportar prejuízos. A amostra é composta por 157 empresas brasileiras de capital aberto, somando 1570 observações no período de 2008 a 2017. Utilizou-se o modelo de Roychowdhury (2006) para mensurar o gerenciamento de resultados. Para a análise dos dados, utilizaram-se os modelos de regressão linear múltipla. Quanto aos resultados, evidenciouse que o gerenciamento de resultado baseado em decisões operacionais foi confirmado nas empresas que apresentaram margem de lucro entre 0 e $1 \%$.
\end{abstract}

Palavras-chave: Gerenciamento de resultados; Decisões operacionais; Reportar prejuízos

\section{Abstract}

The aim of this work was to verify whether Brazilian companies listed in Brazil, Bolsa and Balcão $[\mathrm{B}]^{3}$ used real earnings management to avoid report losses. The sample consists in 157 Brazilian publicly trading companies, totaling 1570 observations from 2008 to 2017. The Roychowdhury model (2006) was used to measure earnings management. For data analysis, multiple linear regression models were used. As for the results, evidence showed that earnings management based on operational decisions was confirmed in companies that presented a profit margin between 0 and $1 \%$.

Keywords: Earnings management; Operational decisions; Report losses

\section{Resumen}

El objetivo de este trabajo fue verificar si las empresas brasileñas que cotizan en Brasil, Bolsa y Balcão [B] ${ }^{3}$ utilizaban la gestión de resultados reales para evitar pérdidas en el informe. La muestra de 157 empresas brasileñas que cotizan en bolsa, con un total de 1570 observaciones de 2008 a 2017. Para medir la gestión de resultados se utilizó el modelo de Roychowdhury (2006). Para el análisis de datos se utilizaron modelos de regresión lineal múltiple. En cuanto a los resultados, la evidencia mostró que la gestión de resultados basada en decisiones operativas se confirmó en empresas que presentaron un margen de utilidad entre 0 y $1 \%$.

Palabras clave: Gestión de resultados; Decisiones operativas; Informar pérdidas

\section{Introdução}

O gerenciamento de resultados é um dos temas de interesse nas pesquisas da área contábil, o que pode ser explicado pela preocupação dos reguladores, acionistas e da mídia em relação ao funcionamento do mercado de capitais e à qualidade dos resultados divulgados pelas entidades (Barton, 2001). 
Na medida em que os gestores estão preocupados em melhorar os indicadores de desempenho atual, eles têm incentivos para inflar seus lucros atuais (Kim \& Sohn, 2013). Podem-se citar incentivos como atender as previsões dos analistas e investidores (Scott, 2012) e manter o lucro estável e previsível (Martinez, 2013). Contudo, a prática de gerenciamento de resultados pode ter outros objetivos, como reduzir a variabilidade dos lucros em virtude de fatores externos, como instabilidade econômica. Portanto, o lucro pode advir das ações de gerenciamento de resultados que distorcem essa medida de desempenho.

Pesquisas envolvendo gerenciamento de resultados comumente focam nos lucros dado a importância desta variável no mercado (Rodrigues, Melo, \& Paulo, 2019). Os gestores julgam o lucro, a métrica central a ser considerada pelos outsiders (Graham, Harvey, \& Rajgopal, 2005). Nesse sentido, Dichev, Graham, Harvey e Rajgopal (2013) verificaram que a principal importância do lucro, na visão dos gestores, refere-se à possibilidade de os investidores avaliarem a empresa, e os dois benchmarks mais significativos são os lucros trimestrais, em relação ao mesmo período do ano anterior, e as estimativas de lucro dos analistas. Além disso, atender ou exceder os benchmarks é pertinente, visto que os executivos acreditam que atingi-los gera credibilidade junto ao mercado (Graham et al., 2005). Nesse raciocínio, eles estão dispostos a praticar o gerenciamento de resultados e sacrificar o desempenho futuro de suas empresas a fim de atender às metas de relatórios financeiros do período atual (Rodrigues et al., 2019).

Em geral, os gerentes deturpam positivamente as informações financeiras da empresa na esperança de distorcer a avaliação do mercado e sinalizar valor positivo, logo, influenciam na percepção dos usuários externos sobre as condições financeiras e econômicas da empresa (Kothari; Mizik, \& Roychowdhury, 2016). Portanto, os relatórios contábeis das empresas têm informações que podem sofrer ajustes por parte dos gestores (Sincerre, Sampaio, Famá, \& Santos, 2016).

As pesquisas que abordam o gerenciamento de resultados indicam que os gerentes têm poder discricionário sobre recursos além de incentivos para divulgar o lucro, ou seja, a discrição e os incentivos estão entrelaçados no cotidiano das empresas (Han, Rezaee, \& Tuo, 2019). Zang (2012) notou que o gerenciamento do lucro é feito inicialmente por atividades operacionais (reais) e, posteriormente, caso necessário, por accruals.

Segundo Roychowdhury (2006), as proxies utilizadas para verificar o gerenciamento por atividades reais são o fluxo de caixa operacional, as despesas com vendas, gerais e administrativas e os níveis de produção. Estudos nacionais (Reis, Cunha \& Ribeiro, 2014; Reis, Lamounier, \& Bressan, 2015; Rodrigues; Paulo \& Melo, 2017) não verificaram a utilização de todas essas proxies pelas empresas brasileiras na prática deste tipo de gerenciamento.

Cohen, Dey e Lys (2008) consideram provável que as empresas que gerenciam os lucros para cima, por meio das atividades operacionais, tenham uma combinação de fluxo de caixa excepcionalmente baixo das operações, e/ou despesas discricionárias baixas e/ou custos de produção excepcionalmente altos.

Rodrigues et al. (2017) e Dal Magro, Lavarda e Klann (2019) destacam que os estudos não têm dado ênfase para o gerenciamento de resultados mediante atividades reais, havendo a necessidade de ampliar 0 número de pesquisas sobre essa vertente. Logo, esse estudo visa suprir parte desta lacuna. Nesse contexto, a questão problema que norteia essa pesquisa é: quando as empresas estão propensas a apresentarem resultados negativos no período, elas fazem uso do gerenciamento de resultados por atividades operacionais?

Assim, o objetivo é verificar se as empresas brasileiras listadas na Brasil, Bolsa, Balcão [B] ${ }^{3}$ evitaram reportar prejuízos baseado no gerenciamento de resultados por atividades operacionais. Especificamente, 0 estudo tem por finalidade verificar se as três proxies de gerenciamento por atividades reais são empregadas pelas empresas.

O trabalho se justifica, pois, a prática de gerenciamento de resultados por decisões operacionais compromete a confiabilidade das demonstrações contábeis e acaba interferindo na tomada de decisão dos stakeholders (Man \& Wong, 2013). Esse estudo traz uma contribuição prática ao apontar o comportamento das organizações na iminência de apresentarem possíveis prejuízos e, por conseguinte, para a tomada de decisão dos usuários da informação contábil. Em relação à contribuição teórica, esse trabalho colobora ao analisar se as formas de gerenciamento de resultados por atividades reais foram todas empregadas.

\section{Fundamentação Teórica}

A contabilidade visa subsidiar a tomada de decisão dos usuários, procurando fornecer informações contábeis fidedignas e confiáveis (Paredes \& Wheatley, 2017). Contudo, os gestores possuem discricionariedade no julgamento de fatos contábeis, podendo alterar as demonstrações financeiras (Kothari et al., 2016). Dal Magro et al. (2019) destacam que a Teoria da Agência tem sido utilizada para guiar a maioria dos estudos sobre gerenciamento de resultados, apresentando duas explicações: o comportamento oportunista dos gestores que visa não demonstrar informações relevantes da contabilidade para as partes interessadas e o reporte da informação contábil usada na comunicação entre as partes.

A Figura 1 resume os principais aspectos a respeito do gerenciamento de resultados. Conforme Lo (2008), podem-se levantar os seguintes questionamentos quanto ao tema: quem faz, por que faz, como faz, modalidades de gerenciamento e quem são as "vítimas". 
Com base na Figura 1, pode-se afirmar que o gerenciamento de resultados se refere às decisões que os gerentes tomam para empregar métodos contábeis ou para direcionar atividades operacionais, de modo a afetar os lucros com a intenção de atingir objetivos específicos em termos dos resultados apresentados nas demonstrações financeiras (Cupertino; Martinez, \& Costa Jr., 2017). Evidências empíricas sugerem que os gerentes tendem a gerenciar os ganhos para benefício pessoal visando a sua reputação externa (Graham et al., 2005).

Os gerentes usam a discricionariedade em relatórios financeiros e nas transações para enganar as partes interessadas no desempenho econômico subjacente da empresa ou influenciar os resultados contratuais que dependem dos números contábeis relatados (Healy \& Wahlen, 1999). Visto dessa forma, os gestores estão manipulando algo que prejudica outro usuário da informação, pois afeta a qualidade do lucro (Cupertino et al., 2017). Nessa lógica, as demonstrações financeiras não são transparentes e nem confiáveis (Scott, 2012). Assim, os lucros reportados que são pertinentes às decisões dos investidores podem não ser úteis para prever o desempenho futuro da empresa (Francis, Lafond, Olsson, \& Schipper, 2005).

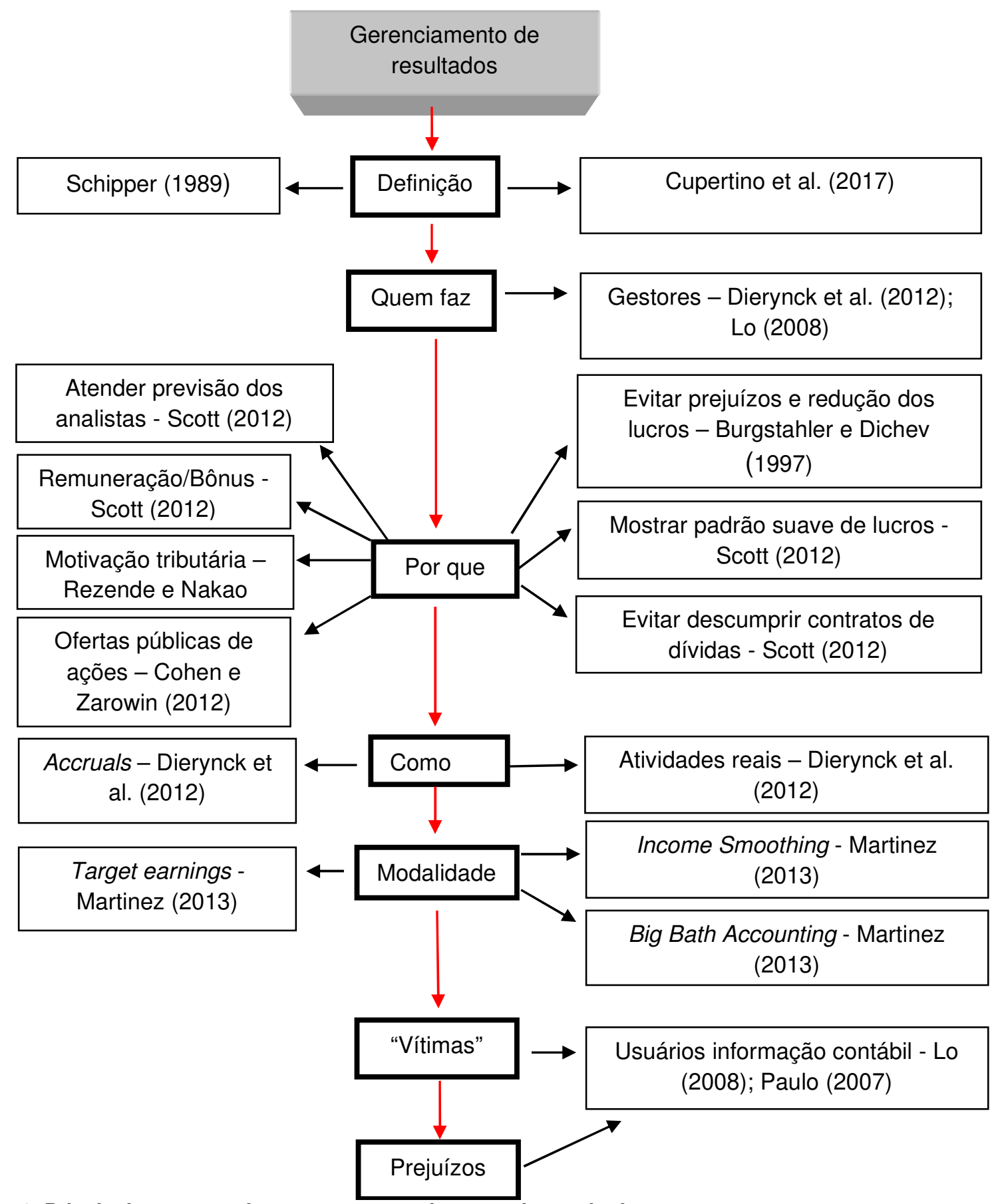

Figura 1: Principais pontos referentes ao gerenciamento de resultados Fonte: elaborado pelos autores.

Isso pode levar a problemas na interpretação dos relatórios financeiros, caso o usuário não saiba identificar o efeito do gerenciamento de resultados nas demonstrações financeiras, pois sua análise pode 
estar equivocada devido aos possíveis ajustes realizados pelos gestores (Sincerre et al., 2016). 0 gerenciamento de resultados é atribuído aos gestores, sendo que pode não ser ocasionado somente por práticas oportunistas de gestores, sendo relevante considerar práticas usuais com relação aos recursos organizacionais (Dierynck, Landsman, \& Renders, 2012; Lo, 2008).

As evidências mostram que as empresas gerenciam os resultados para evitar reportar prejuízos ou reduzir o lucro (Burgstahler \& Dichev, 1997), mostrar um padrão suave de ganhos, atender às previsões de lucros dos analistas, ou a fim de evitar descumprir os contratos de dívidas (Scott, 2012). Para Healy e Wahlen (1999) as motivações para gerenciar relacionam-se com os mercados de capitais, às relações contratuais ou às regulamentações e aos custos políticos. Martinez (2013) cita como possibilidades suavizar os resultados reportados, atender à expectativa de analistas, manter a tendência ou esquivar-se de divulgar prejuízos incorridos no período. Cohen e Zarowin (2010) encontraram evidências de que ocorre gerenciamento de resultados por parte das empresas americanas, próximo ao período de ofertas públicas de ações.

O interesse dos gerentes em gerenciar resultados decorre, em parte, do fato que o resultado é utilizado para uma variedade de finalidades (obrigações contratuais, avaliação de ativos, planos de bônus e remuneração de executivos) e como as demonstrações financeiras resumem as informações relevantes do desempenho da empresa, o lucro apresentado é de suma importância (Dani, Dal Magro \& Klann, 2017).

A literatura identifica duas estratégias principais para gerenciar os ganhos reportados: (1) baseadas em accruals (AEM), que não têm efeito direto nas atividades operacionais e nos fluxos de caixa e (2) atividades reais, que afetam os fluxos de caixa (Dierynck et al., 2012).

No gerenciamento de resultados com base em accruals, os gerentes intervêm no processo de relatório financeiro, exercendo discrição e julgamento em relação às estimativas e aplicação das normas contábeis (Kothari et al., 2016). Esse gerenciamento de resultados normalmente ocorre no final de um período contábil, após a conclusão da maioria das atividades operacionais reais (Kim \& Sohn, 2013; Zang, 2012).

As possibilidades de seleção de alternativas para mensurar os ativos conforme as normas geram os accruals (Silva \& Fonseca, 2015). Defond e Jiambalvo (1994) os definem como a diferença entre o lucro líquido e o fluxo de caixa operacional. Portanto, accruals são as contas de resultado que entraram no cômputo do lucro, mas que não acarretaram alterações no fluxo de caixa (Martinez, 2008). O uso de julgamentos oportuniza aos gestores ter escolhas contábeis, denominadas discricionárias, que não refletem de maneira adequada a realidade econômico-financeira da empresa (Healy \& Wahlen, 1999). Destaca-se que a não discricionariedade são os lançamentos contábeis naturais do negócio (Martinez, 2008).

A manipulação de atividades reais, por outro lado, acarreta desvios das operações normais com a intenção de apresentar o desempenho financeiro relatado como decorrente do curso normal das operações (Roychowdhury, 2006). Similar aos accruals, as operações reais podem ser usadas para esconder más notícias sobre desempenho e perspectivas (Francis, Hasan \& Li, 2016).

Acerca do gerenciamento por meio das atividades reais, existem diferentes possibilidades que podem ser utilizadas para as empresas esquivarem-se de anunciar perdas do período: (1) manipulação de vendas, aumentando as vendas por meio de descontos de preços e/ou condições de crédito mais favoráveis; (2) redução das despesas discricionárias (despesas de vendas e administrativas, publicidade, pesquisa e desenvolvimento); (3) escolha dos momentos para realizar investimentos e o período oportuno de reconhecer valores provenientes de alienação de ativos; (4) superprodução, quando a empresa produz mais que o necessário, reduzindo o custo das vendas, de forma a obter melhores margens operacionais (Gunny, 2010, Reis et al., 2014; Roychowdhury, 2006).

Evidências empíricas sustentam que, enquanto os níveis esperados normais de atividades reais estão associados a decisões operacionais racionais, os níveis anormais estão associados a decisões subótimas baseadas em oportunismo gerencial para aumentar lucros (Kim; Sohn, 2013). Considerando o gerenciamento por atividades reais, existe a preocupação de que as empresas que desviem das práticas comerciais normais possam ter um impacto negativo nos fluxos de caixa e no desempenho futuro (Paredes \& Wheatley, 2017).

Os estudos sobre gerenciamento de resultados têm sido majoritariamente direcionados aos modelos de accruals, mas há uma tendência de aplicação do modelo de atividades reais (Vladu \& Cuzdriorean, 2014). Cohen, Dey e Lys (2008) examinaram o impacto da passagem da Lei Sarbanes-Oxley (SOX) na preferência dos gerentes por gerenciamento de accruals ou atividades reais. Os autores documentam que as empresas estavam fortemente envolvidas em AEM no período pré-SOX, mas que este envolvimento diminuiu significativamente após a passagem para a SOX. Zang (2012) argumenta que as mudanças no rigor das normas contábeis devido à SOX não implicam necessariamente em redução de gerenciamento de resultados, mas apenas uma alteração do método utilizado.

Dal Magro et al. (2019) verificaram que a maioria dos estudos está focada na gestão de resultados por accruals, e que o uso de atividades reais como forma de gestão de resultados é incipiente. Por sua vez, Cupertino et al. (2017) notaram que o nível de manipulação por accruals reduziu após a adoção das Normas Internacionais de Contabilidade (IFRS) no Brasil, enquanto que por meio de atividades reais aumentou. Eles destacam ainda que, no cenário nacional, pouco se conhece a respeito de cada uma destas duas estratégias de manipulação de resultados.

A princípio, há um trade-off entre gerenciamento de resultados por accruals e atividades reais (Cohen \& Zarowin, 2010, Paulo \& Mota, 2019). Zang (2012) evidenciou que os gerentes usam a manipulação de 
atividades reais e o gerenciamento com base em accruals como substitutos. Isso pode ser explicado, em parte, porque o custo de gerenciamento difere entre esses métodos, e o gerenciamento por meio de atividades reais é considerado mais oneroso porque destrói o fluxo de caixa (Roychowdhury, 2006).

Todavia, a evidência empírica parece inconsistente com o custo mais alto do gerenciamento de resultados reais, pois os gerentes estão mais dispostos a se engajar nesta categoria de gerenciamento do que no gerenciamento de accruals (Graham et al., 2005). Em particular, os resultados da pesquisa de Graham et al. (2005) mostram que os gestores estão dispostos a gastar os recursos do caixa e fazer sacrifícios econômicos para atingir as metas de lucro. Possíveis explicações referem-se ao fato de que confiar apenas na manipulação por accruals é arriscado e a capacidade de detecção do gerenciamento por meio de atividades reais é mais difícil (Cohen \& Zarowin, 2010; Kothari et al., 2016), além de serem normalmente menos sujeitas a monitoramento externo e da auditoria (Cohen et al., 2008; Kim \& Sohn, 2013). Isso se deve ao fato de que os accruals estão sujeitos à verificação por parte dos auditores que têm padrões contábeis como referência (Cohen \& Zarowin, 2010). Cupertino et al. (2017) consideram razoável supor que uma combinação de accruals e de gerenciamento por atividades reais será usada para manipular os resultados. Zang (2012) notou que o ajuste do lucro é feito inicialmente por atividades operacionais e, posteriormente, caso necessário, por accruals.

Com base no gerenciamento por accruals e/ou atividades reais, os gestores podem gerenciar o lucro de acordo com seus objetivos. As modalidades de gerenciamento de resultados conforme o interesse do gestor é destacado por Martinez (2001): Target Earnings, Income Smoothing e Big Bath Accounting. A modalidade Target Earnings (lucro alvo) tem o objetivo de aumentar (utilizada na remuneração dos administradores, covenants de endividamento) ou diminuir (para reduzir a carga tributária) os resultados contábeis a fim de atingir metas específicas. Na modalidade Income Smoothing, o gerenciamento ocorre para reduzir a variabilidade dos lucros contábeis em determinados períodos com a finalidade de que os mesmos permaneçam estáveis e não apresentem oscilação excessiva, ou seja, a suavização. Ela tem como objetivo transparecer menor risco para o investidor. Quanto à modalidade Big Bath Accounting, esta tem a finalidade de reduzir o lucro corrente para aumentar a probabilidade de bons lucros futuros quando da modificação da cúpula administrativa, ou seja, as empresas buscam piorar seus resultados correntes para obter melhores resultados no futuro.

Paulo (2007) destaca prejuízos do gerenciamento de resultados a alguns atores interessados nas demonstrações financeiras, como, por exemplo:

a) Investidores: não possuem informações confiáveis para auxiliá-los na decisão de investimento, podendo ter uma parcela de sua riqueza expropriada pelos gestores;

b) Analistas financeiros: apresentam recomendações de investimentos aos seus clientes de forma ineficiente devido à estimação incorreta dos resultados;

c) Instituições de crédito: não têm a verdadeira percepção sobre os riscos inseridos em suas negociações;

d) Entidades reguladoras do mercado: veem tal prática prejudicar o funcionamento adequado do mercado;

e) Entidades fazendárias: podem ser prejudicadas por tal comportamento uma vez que ele seria utilizado como forma de sonegação tributária;

f) Entidades sindicais: as informações sobre a situação econômica e financeira da empresa não são confiáveis, dificultando as negociações trabalhistas.

Kothari et al. (2016) sugerem que a capacidade dos investidores de detectar o gerenciamento de resultados e avaliar suas consequências para o desempenho futuro é prejudicada quando as atividades reais são à base do gerenciamento de resultados. Outsiders têm capacidade limitada para distinguir decisões operacionais oportunistas de decisões legítimas feitas de boa-fé, sendo que essa assimetria informacional fornece aos gerentes as oportunidades para ocultar notícias negativas (Francis et al., 2016).

Diante deste cenário, estudos têm sidos realizados sobre o tema. Roychowdhury (2006) investigou a utilização do gerenciamento por atividades reais e encontrou evidências do uso da estratégia para evitar reportar prejuízos incorridos. Os resultados indicaram níveis mais baixos de fluxo de caixa operacional e despesas discricionárias, e níveis mais altos de custo de produção.

Gunny (2010) verificou que os gestores fizeram uso do gerenciamento por atividades reais e que a manipulação dessas atividades afeta o desempenho subsequente. Nesse sentido, Cohen e Zarowin (2010) examinaram as formas de gerenciamento de resultados (accruals e decisões operacionais) próximas das ofertas secundárias de ações. Os autores concluíram que os gestores utilizam de ambas as estratégias, e que o declínio na perfomance posterior decorre principalmente do gerenciamento por decisões operacionais. Soma-se a isso a constatação de Cupertino, Martinez e Costa Jr. (2016) de que, há uma relação negativa 
entre o gerenciamento de resultados por decisões operacionais e a rentabilidade futura das empresas brasileiras.

Zang (2012) demonstrou que as empresas utilizam as duas formas de gerenciamento como substitutas, conforme os custos atribuídos a cada uma. Nessa lógica, Cupertino et al. (2017) verificaram que nas empresas brasileiras a adoção das estratégias depende do custo relativo de cada uma e que o gerenciamento por decisões operacionais precede o de accruals, bem como tem aumentado após a adoção das normas internacionais de contabilidade.

Reis, Cunha e Ribeiro (2014) verificaram se as empresas que compõem o Índice Brasil (IBrX) gerenciam resultados baseados em decisões operacionais. Os autores apontaram que as empresas não utilizaram o volume de vendas e os níveis de produção para aumentar ou reduzir os resultados contábeis. Por outro lado, o estudo de Reis et al. (2015) mostrou que as empresas brasileiras listadas na [B] ${ }^{3}$ utilizaram das despesas com vendas, gerais e administrativas para evitar reportar prejuízos. Rodrigues et al. (2017) também constataram que as empresas brasileiras com valores de mercado acima da média, possuem maiores níveis de manipulação de vendas e diminuição de despesas com vendas, gerais e administrativas.

Roychowdhury (2006), Gunny (2010) e Reis et al. (2015) evidenciam que empresas que apresentam uma margem de lucro positiva, mas próxima de zero, incorrem em gerenciamento de resultados por meio de decisões operacionais. Assim, infere-se a seguinte hipótese:

$\mathrm{H}_{1}$ : As empresas que apresentaram margens de lucro entre 0 e $1 \%$ utilizaram do gerenciamento de resultados mediante atividades operacionais.

Para verificar a hipótese apresentada, as informações obtidas das demonstrações financeiras serviram de proxies conforme descrito nos procedimentos metodológicos.

\section{Procedimentos Metodológicos}

A população correspondeu a todas as empresas ativas listadas na $[B]^{3}$ no período de 2008 a 2017 . A escolha desse período deve-se ao fato de serem necessárias informações relacionadas ao fluxo de caixa operacional disponibilizadas na Demonstração do Fluxo de Caixa, a qual foi exigida por lei a partir do ano de 2008 (Reis et al., 2015). O ano 2017 refere-se aos últimos dados disponíveis na Economática ${ }^{\circledR}$ no momento da coleta. As informações coletadas foram as consolidadas, ajustadas pelo índice de inflação da própria base de dados - Índice de Preços ao Consumidor Amplo (IPCA) e mensuradas em milhões de reais, com dados anuais referentes a dezembro de cada ano.

Procedeu-se à exclusão de empresas pertencentes ao setor Finanças e Seguros conforme a classificação da base Economática ${ }^{\circledR}$ porque operam em setores altamente regulamentados com regras contábeis específicas que diferem dos outros setores, levando a diferenças na interpretação dos relatórios financeiros (Cupertino et al., 2017; Gunny, 2010; Johnson, 2016; Zang, 2012).

Para atenuar o problema dos dados faltantes foram excluídas as empresas que não tinham informações referentes à receita em pelo menos cinco períodos, por exemplo, empresas com negociações recentes na bolsa. Como são necessárias informações referentes à variação da receita líquida em $t$-2 no modelo de gerenciamento por atividades reais, as empresas precisaram disponibilizar os dados, pelo menos, em três anos consecutivos. Assim, as empresas que tinham dados faltantes, em um ou dois períodos apenas, tiveram esses valores obtidos via imputação de dados, por meio da média dos três períodos subsequentes.

Conforme Banker, Byzalov e Plehn-Dujowich (2014), foram excluídas da amostra empresas que apresentaram variação da receita líquida igual ou superior a $50 \%$ entre o período de um exercício e o subsequente, pois podem significar reestruturações produtivas ou até mesmo fusões, aquisições e outras operações especiais. Também foram excluídas duas empresas que apresentavam dados ausentes para receitas. Por fim, a amostra compreendeu 157 empresas, totalizando 1570 observações.

Inicialmente, para definir as empresas suspeitas de gerenciamento de resultados por atividades reais, empregou-se a metodologia de distribuição de frequência de acordo com Gunny (2010) e Zang (2012). Para isso, utilizou-se a margem de lucro (lucro líquido do período dividido pelo ativo total do período), dividindo-a em percentil, sendo consideradas suspeitas de gerenciar o resultado contábil as empresas que apresentaram margem de lucro positiva entre 0 e $1 \%$ em cada período, visto que as empresas podem gerenciar os resultados em um ano e em outro não (Reis et al., 2015). Além do mais, segundo Burgstahler e Dichev (1997), as firmas evitam anunciar pequenos prejuízos, pois estes podem representar um sinal de desempenho fraco e preferem reportar pequenos lucros.

De acordo com Reis et al. (2015) as empresas que apresentam margem de lucro positiva, porém próxima a zero podem ter gerenciado seus lucros porque o zero refere-se ao benchmark. Graham et al. (2005) destacam que os gestores estão dispostos a atender esse benchmark uma vez que a divulgação de prejuízos pode indicar uma má gestão, gerando dúvidas sobre as perspectivas futuras da empresa. Dessa forma, adotase uma postura conservadora no uso do termo REM (gerenciamento por atividades reais) ao longo deste trabalho: refere-se apenas às firmas suspeitas que relatam lucros positivos que estão próximos de zero, isto é, evitam divulgar prejuízos incorridos no período (Francis et al., 2016).

O modelo de gerenciamento utilizado para detectar a manipulação por atividades reais foi implementado por Roychowdhury (2006) e aplicado nos estudos de Cohen et al. (2008), Cohen e Zarowin 
(2010), Cupertino et al. (2017) e Zang (2012). Esse modelo é baseado em três métricas: fluxo de caixa das operações (FCO), nível de produção (PROD) e despesas discricionárias (DD), conforme as equações $1,2 \mathrm{e}$ 3 , respectivamente.

$$
\begin{aligned}
& \frac{\mathrm{FCO}_{i t}}{\mathrm{~A}_{i, t-1}}=\beta_{0}+\beta_{1} \frac{1}{\mathrm{~A}_{i, t-1}}+\beta_{2} \frac{\mathrm{RL}_{i t}}{\mathrm{~A}_{i, t-1}}+\beta_{3} \frac{\Delta \mathrm{RL}_{i t}}{\mathrm{~A}_{i, t-1}}+\varepsilon_{i, t}, \\
& \frac{\mathrm{PROD}_{i t}}{\mathrm{~A}_{i, t-1}}=\beta_{0}+\beta_{1} \frac{1}{\mathrm{~A}_{i, t-1}}+\beta_{2} \frac{\mathrm{RL}_{i t}}{\mathrm{~A}_{i, t-1}}+\beta_{3} \frac{\Delta \mathrm{RL}_{i t}}{\mathrm{~A}_{i, t-1}}+\beta_{4} \frac{\Delta \mathrm{RL}_{i t-1}}{\mathrm{~A}_{i, t-1}}+\varepsilon_{i, t}, \\
& \frac{\mathrm{DD}_{i t}}{\mathrm{~A}_{i, t-1}}=\beta_{0}+\beta_{1} \frac{1}{\mathrm{~A}_{i, t-1}}+\beta_{2} \frac{\mathrm{RL}_{i t-1}}{\mathrm{~A}_{i, t-1}}+\varepsilon_{i, t},
\end{aligned}
$$

\section{Em que:}

$\mathrm{FCO}_{i t}$ : Fluxo de caixa operacional da empresa $i$ no período $t, \mathrm{PROD}_{i t}$ : Custo do produto vendido + variação dos estoques da empresa $i$ no período $t ; \mathrm{DD}_{i t}$ : Despesas com vendas, gerais e administrativas da empresa $i$ no período $t ; \mathrm{A}_{i t-1}$ : Total do ativo da empresa $i$ no período $t-1$; $\mathrm{RL}_{i t}$ : Receita líquida da empresa $i$ no período $t ; \Delta \mathrm{RL}_{i t}$ : Variação na receita líquida da empresa $i$ do período $t$ em relação ao $t-1$; $\Delta \mathrm{RL}_{i t-1}$ : Variação na receita líquida da empresa $i$ do período $t-1$ em relação ao $t-2 ; \varepsilon_{i t}:$ Representa o erro.

As variáveis dos modelos 1,2 e 3 estão padronizadas pelo ativo total como forma de amenizar problemas de heterocedasticidade, inerentes à estimação com os dados em painel, e a inclusão do intercepto padronizado permite que a variável independente se distinga de zero mesmo quando não há vendas para o período t ou $t-1$ (Roychowdhury, 2006). Esses modelos estimam o nível "normal" de atividades reais e, como resultado, os resíduos da regressão representam o nível "anormal", isto é, proxies para variáveis de gerenciamento de resultados por meio de atividades reais (Francis et al., 2016).

O nível normal do FCO (equação 1) é uma função linear das receitas de vendas e da variação das receitas de vendas. Esse modelo detecta a manipulação de vendas por meio de descontos de preços ou oferta de condições de crédito mais favoráveis, gerando, temporariamente, maiores fluxos de caixa que são diminuídos quando a atividade normal das operações é restabelecida (Francis et al., 2016). Assim, espera-se que $\beta_{2}$ e $\beta_{3}$ possuam valores positivos, pois quanto mais a empresa aumenta a sua receita, seu FCO deve aumentar, contudo, se o $\beta_{3}$ for significativo e negativo isso indicará suspeitas de gerenciamento de resultados por meio de manipulação das vendas.

A segunda proxy empregada para identificar a manipulação por atividades reais é o nível de produção (equação 2), que pode ser aplicada a qualquer setor (Martinez \& Cardoso, 2009). Espera-se que todos os coeficientes desse modelo sejam positivos, pois pressupõe-se que as vendas e os níveis de produção aumentem proporcionalmente (Almeida-Santos, Verhagem \& Bezerra, 2011). A análise pelos custos de produção ao invés dos custos dos produtos vendidos evita a influência do gerenciamento por accruals (Cupertino et al., 2017; Gunny, 2010). Paredes e Wheatley (2017) evidenciam que uma superprodução associada a uma redução nas vendas é um indicativo de gerenciamento de resultados.

A proxy do gerenciamento das despesas discricionárias (equação 3) para o exercício atual é uma função do nível atual de vendas, e o resíduo da regressão reflete a magnitude da manipulação obtida, cortando despesas com vendas, gerais e administrativas. Portanto, espera-se que o coeficiente $\beta_{2}$ tenha sinal positivo, pois quanto mais a empresa vende seus produtos, maiores são os valores das despesas com vendas.

Conforme Ge e Kim (2014), Reis et al. (2015) e Rodrigues et al. (2017), os resíduos das equações 1 , 2 e 3 foram utilizados como variáveis dependentes nos modelos 4, 5 e 6 que estimam os níveis anormais denominados AFCO, APROD e ADD.

$$
\begin{aligned}
& A F C O_{i t}=y_{0}+\mathrm{y}_{1} \mathrm{D}_{\mathrm{it}}+\mathrm{y}_{2} \mathrm{TAM}_{\mathrm{it}}+\mathrm{y}_{3} \mathrm{MTB}_{\mathrm{it}}+\mathrm{y}_{4} \mathrm{ROA}_{\mathrm{it}}+\varepsilon_{i, t} \\
& A P R O D_{i t}=y_{0}+\mathrm{y}_{1} \mathrm{D}_{\mathrm{it}}+\mathrm{y}_{2} \mathrm{TAM}_{\mathrm{it}}+\mathrm{y}_{3} \mathrm{MTB}_{\mathrm{it}}+\mathrm{y}_{4} \mathrm{ROA}_{\mathrm{it}}+\varepsilon_{i, t} \\
& A D D_{i t}=y_{0}+\mathrm{y}_{1} \mathrm{D}_{\mathrm{it}}+\mathrm{y}_{2} \mathrm{TAM}_{\mathrm{it}}+\mathrm{y}_{3} \mathrm{MTB}_{\mathrm{it}}+\mathrm{y}_{4} \mathrm{ROA}_{\mathrm{it}}+\varepsilon_{i, t} \\
& R E M_{i t}=y_{0}+\mathrm{y}_{1} \mathrm{D}_{\mathrm{it}}+\mathrm{y}_{2} \mathrm{TAM}_{\mathrm{it}}+\mathrm{y}_{3} \mathrm{MTB}_{\mathrm{it}}+\mathrm{y}_{4} \mathrm{ROA}_{\mathrm{it}}+\varepsilon_{i, t}
\end{aligned}
$$

Em que:

$\mathrm{AFCO}_{i t}$ : Nível anormal de FCO da empresa $i$ no período $t$; APROD $_{i t}$ Nível anormal de PROD da empresa $i$ no período $t$; ADD $_{i t}$ : Nível anormal de DD da empresa $i$ no período $t$; REMit: Medida agregada (equação 9) da empresa $i$ no período $t$; $D_{i t:}$ : Variável dummy que assume valor 1 para as empresas que apresentaram margem de lucro entre zero e $1 \%$ e 0 , caso contrário, da empresa $i$ no período $t$; $\mathrm{TAM}_{i t}$ : Logaritmo natural do total dos ativos da empresa $i$ no período $t$; MTB $_{i t:} \mathrm{O}$ valor de mercado do capital dividido pelo patrimônio líquido da empresa $i$ no período $t, \mathrm{ROA}_{i t}$ : Lucro líquido dividido pelo total dos ativos da empresa $i$ do período $t$; $\varepsilon_{i t}$ : Representa 0 erro.

De acordo com Gunny (2010) e Zang (2012), para as empresas suspeitas espera-se um fluxo de caixa baixo devido aos descontos nos preços dos produtos vendidos. O coeficiente $y_{1}$ da equação 4 verifica se as empresas aumentaram o volume de vendas, apresentando menor fluxo de caixa. Se o coeficiente $y_{1}$ 
for significativo e negativo, confirma-se a suspeita e as empresas usam o gerenciamento de resultados operacionais em vendas por meio de descontos nos preços.

Gunny (2010) destaca que os custos de produção anormalmente altos para um determinado nível de vendas são indicativos de manipulação de vendas. Para verificar se as empresas suspeitas aumentaram o nível de produção de forma a gerenciar o resultado, espera-se que o coeficiente $y_{1}$ da equação 5 seja significativo e positivo.

Para Gunny (2010) e Zang (2012) as empresas que utilizam o gerenciamento de resultados para aumentar os números nos relatórios provavelmente utilizam valores baixos de despesas discricionárias. Quando verificadas as empresas suspeitas, espera-se que o coeficiente $y_{1}$ da equação 6 seja significativo e negativo, ou seja, que essas empresas apresentem de forma anormal menores despesas com vendas, gerais e administrativas.

Dados os níveis de vendas, é provável que as empresas que gerenciam os lucros para cima tenham: um fluxo de caixa excepcionalmente baixo das operações e/ou despesas discricionárias baixas e/ou custos de produção excepcionalmente altos (Cohen et al., 2008). Conforme Ge e Kim (2014), para capturar os efeitos do gerenciamento de resultados dessas três atividades em uma medida abrangente, construiu-se uma proxy de gerenciamento de resultado global (REM) somando as três proxies anormais (AFCO, APROD e ADD) conforme a equação 8 (Cohen \& Zarowin, 2010; Cupertino et al., 2017; Ge \& Kim, 2014; Zang, 2012). Como todas essas medidas são padronizadas pelo total de ativos para o período financeiro anterior, elas podem ser somadas e o resultado comparado entre empresas de diferentes tamanhos (Cupertino et al., 2017).

$\mathrm{REM}_{i t}=(\mathrm{APROD})+((\mathrm{AFCO}+\mathrm{ADD}) *(-1))$

Em que:

REM $_{i t}$ : Gerenciamento de resultados por atividades reais da empresa $i$ no período $t ;$ APROD $_{i t}$ Nível anormal de PROD da empresa $i$ no período $t$; $\mathrm{AFCO}_{i t:}$ Nível anormal de FCO da empresa $i$ no período $t ; \mathrm{ADD}_{i t}$ : Nível anormal de DD da empresa $i$ no período $t$.

Multiplicaram-se os resultados das equações 4 e 6 por -1, de tal forma que valores mais altos indiquem uma maior possibilidade de tomar decisões reais para aumentar os ganhos (Cohen \& Zarowin, 2010; Zang, 2012). A equação 5 não foi multiplicada por -1 , pois os custos de produção mais altos são indicativos de superprodução e alto grau de gerenciamento (Cupertino et al., 2016; Zang, 2012). Assim, espera-se que o coeficiente $y_{1}$ da equação 7 seja significativo e negativo, ou seja, as empresas suspeitas de gerenciar o resultado contábil incorreram no gerenciamento de resultados por atividades reais de maneira anormal.

As variáveis de controle são apresentadas no Tabela 1. Empresas maiores apresentam uma série de características corporativas que as diferenciam das menores, por exemplo, uma gama mais diversificada de produtos, uso extensivo dos mercados de capitais para financiamento e maior visibilidade. Esses dois últimos aspectos são de particular importância para a quantidade e qualidade das informações divulgadas devido à interação com diferentes stakeholders. Nesse sentido, grandes empresas apresentam uma elevada escala de operação, que proporciona oportunidades e incentivos para os gestores desviarem-se dos objetivos do principal, isto é, grandes empresas podem ter maiores conflitos de agência (Scott, 2012).

Tabela 1:

Variáveis de controle

\begin{tabular}{l|l|l|l}
\hline \multicolumn{1}{c|}{ Variável } & \multicolumn{1}{|c|}{ Descrição } & \multicolumn{1}{c}{ Fórmula } & \multicolumn{1}{c}{ Autores } \\
\hline $\begin{array}{l}\text { TAMit } \\
\text { tamanho }\end{array}$ & $\begin{array}{l}\text { Proxy do tamanho da } \\
\text { empresa } i \text { no período } t .\end{array}$ & LN Ativo Total. & $\begin{array}{l}\text { Cupertino et al. (2017), Gunny (2010), } \\
\text { Reis et al. (2015), Roychowdhury (2006), } \\
\text { Sincerre et al. (2016). }\end{array}$ \\
\hline $\begin{array}{l}\text { ROA } i t \\
\begin{array}{l}\text { Retorno sobre } \\
\text { ativos }\end{array}\end{array}$ & $\begin{array}{l}\text { Proxy de retorno } \\
\text { sobre o investimento da } \\
\text { empresa } i \text { no período } t .\end{array}$ & Lucro Líquido/Total Ativo. & $\begin{array}{l}\text { Cupertino et al. (2017), Gunny (2010), } \\
\text { Reis et al. (2015), Sincerre et al. (2016), } \\
\text { Zang (2012). }\end{array}$ \\
\hline $\begin{array}{l}\text { MTB } i t-\text { Market } \\
\text { to Book }\end{array}$ & $\begin{array}{l}\text { Proxy da taxa de } \\
\text { crescimento da empresa } i \\
\text { no período } t .\end{array}$ & $\begin{array}{l}\text { Valor } \\
\text { Ações/Patrimônio Líquido } \\
\text { por ação. }\end{array}$ & $\begin{array}{l}\text { Cupertino et al. (2017), Reis et al. (2015), } \\
\text { Roychowdhury (2006), Zang (2012). }\end{array}$ \\
\hline
\end{tabular}

Fonte: elaborado pelos autores.

A proxy utilizada para registrar o efeito do desempenho da empresa foi o retorno sobre os ativos (ROA), pois por meio do gerenciamento de resultados é possível aumentar ou diminuir o lucro contábil e um ROA baixo indica desempenho fraco e problemas de agência (Paulo \& Mota, 2019). A variável Market-toBook está ligada ao mercado de capitais e às perspectivas que os acionistas possuem em relação à empresa. Skinner e Sloan (2002) documentam que as empresas com oportunidades de crescimento são mais penalizadas pelo mercado de ações quando perdem os limites de lucros. Dessa forma, é provável que as empresas com crescimento também experimentem pressão para gerenciar os resultados (Roychowdhury, 2006). Nesse sentido, Rodrigues et al. (2017) constataram que empresas com valor de mercado acima da média, medido pelo índice Market-to-book, possuem maiores níveis de manipulação de vendas.

Como se utilizam de dados em painel para estimar as proxies de gerenciamento, é necessário determinar a melhor especificação dos modelos de efeitos constantes (pooled), efeitos fixos e efeitos 
aleatórios. Bressan, Braga, Bressan e Resende-Filho (2012) destacam os procedimentos: primeiro estimar os modelos constante (pooled) e efeitos fixos para testar, via teste Chow (teste F), a hipótese nula de que o modelo constante é preferível a efeitos fixos.

No segundo passo, estima-se o modelo com efeitos aleatórios e, ao utilizar o teste Breusch-Pagan (teste do tipo multiplicador de Lagrange), testa-se a hipótese nula de que o modelo pooled é preferível ao modelo com efeitos aleatórios.

O terceiro passo consiste em testar, pelo teste de Hausman, a hipótese nula de que o estimador de efeitos aleatórios, por ser consistente e eficiente, é preferível ao estimador do modelo com efeitos fixos que é apenas consistente.

Posteriormente à escolha do modelo mais adequado, executa-se o quarto passo que consiste em testar a autocorrelação dos erros via teste Wooldridge e testar a heterocedasticidade pelo teste de Wald e Breusch-Pagan. No caso de evidências de autocorrelação e heterocedasticidade, estima-se a regressão por meio robusto para a correção.

\section{Resultados e Discussão}

A Tabela 2 resume os modelos utilizados e os testes de autocorrelação, heterocedasticidade e multicolinearidade para cada equação. Percebe-se que não houve heterocedasticidade somente na equação 4. Em todos os demais modelos ocorreram autocorrelação e heterocedasticidade, sendo empregada a correção por meio robusto. A multicolinearidade ocorre quando variáveis explicativas mensuram a mesma coisa e valores da estatística Variance Inflation Factor (VIF) acima de 10 indicam perfeita multicolinearidade (Gujarati \& Porter, 2011). Nenhuma das equações presentes na Tabela 2 apresentou multicolinearidade substancial (VIF entre 1,01 e 2,24).

Tabela 2:

Testes da seleção dos modelos, autocorrelação, heterocedasticidade e multicolinearidade

\begin{tabular}{|c|c|c|c|c|}
\hline $\begin{array}{l}\text { Equação/Modelo } \\
\text { utilizado }\end{array}$ & $\begin{array}{l}\text { Testes aplicados para definir o } \\
\text { modelo }\end{array}$ & Autocorrelação ${ }^{1}$ & $\underset{2}{\text { Heterocedasticidade }}$ & $\underset{3}{\text { Multicolinearidade }}$ \\
\hline $\begin{array}{l}1-\text { FCO / Efeitos } \\
\text { aleatórios }\end{array}$ & $\begin{array}{l}\text { Chow } F(156,1410)=1,29 \text { e } \\
\text { valor- } p=0,0120 \\
\text { Hausmann } \chi^{2}(3)=2,26 \mathrm{e} \\
\text { valor-p }=0,5200\end{array}$ & $\begin{array}{l}\text { Sim. } F(1,156)= \\
8,787 \text { e valor-p } \\
=0,0035 .\end{array}$ & $\begin{array}{l}\text { Sim. } \chi^{2}(157)= \\
6,1 e+09 \text { e valor-p }= \\
0,0000 .\end{array}$ & 1,71 \\
\hline $\begin{array}{l}\text { 2- PROD / Efeitos } \\
\text { fixos }\end{array}$ & $\begin{array}{l}\text { Chow } F(156,1409)=1,38 \mathrm{e} \\
\text { valor- } \mathrm{p}=0,0020 ; \\
\text { Hausmann } \chi^{2}(4)=11,77 \mathrm{e} \\
\text { valor-p }=0,0191\end{array}$ & $\begin{array}{l}\text { Sim. } F(1,156)= \\
272,320 \text { e valor- } \\
p=0,0000\end{array}$ & $\begin{array}{l}\text { Sim. } \chi^{2}(157)= \\
1,1 e+12 \text { e valor-p }= \\
0,0000\end{array}$ & 2,24 \\
\hline 3- DD / Efeitos fixos & $\begin{array}{l}\text { Chow } F(156,1411)=1,28 \mathrm{e} \\
\text { valor-p = 0,0144; } \\
\text { Hausmann } \chi^{2}(2)=6,67 \mathrm{e} \\
\text { valor-p }=0,0356\end{array}$ & $\begin{array}{l}\text { Sim. } F(1,156)= \\
238753,980 \text { e } \\
\text { valor-p }= \\
0,0000 .\end{array}$ & $\begin{array}{l}\text { Sim. } \chi^{2}(157)= \\
1,2 e+11 \text { e valor-p }= \\
0,0000\end{array}$ & 1,05 \\
\hline 4 - AFCO / Pooled & $\begin{array}{l}\text { Chow } F(156,1409)=1,09 \text { e } \\
\text { valor- } p=0,2126 ; \text { Lagrange } \\
\chi^{2}(1)=0,02 \text { e valor- } p= \\
0,4386 .\end{array}$ & $\begin{array}{l}\text { Sim. } F(1,156)= \\
1,416 e+06 \text { e } \\
\text { valor-p }= \\
0,0000 .\end{array}$ & $\begin{array}{l}\text { Não. } \chi^{2}(1)=3,95 \mathrm{e} \\
\text { valor-p }=0,0468 .\end{array}$ & 1,01 \\
\hline 5-APROD / Pooled & $\begin{array}{l}\text { Chow } F(156,1409)=1,05 \text { e } \\
\text { valor- } p=0,3155 ; \text { Lagrange } \\
\chi^{2}(1)=0,04 \text { e valor- } p= \\
0,4221\end{array}$ & $\begin{array}{l}\text { Sim. } F(1,156)= \\
33805,889 \text { e } \\
\text { valor-p = } \\
0,0000 .\end{array}$ & $\begin{array}{l}\text { Sim. } \chi^{2}(1)=157,66 \\
\text { e valor-p }=0,0000\end{array}$ & 1,01 \\
\hline 6-ADD / Pooled & $\begin{array}{l}\text { Chow } F(156,1409)=1,13 \text { e } \\
\text { valor- } p=0,1408 ; \text { Lagrange } \\
\chi^{2}(1)=0,16 \text { e valor- } p= \\
0,3432 .\end{array}$ & $\begin{array}{l}\text { Sim. } F(1,156)= \\
1,012 e+06 \mathrm{e} \\
\text { valor-p }= \\
0,0000\end{array}$ & $\begin{array}{l}\text { Sim. } \chi^{2}(1)=27,41 \text { e } \\
\text { valor- } p=0,0000 .\end{array}$ & 1,01 \\
\hline 7 - REM / Pooled & $\begin{array}{l}\text { Chow } F(156,1409)=1.01 \text { e } \\
\text { valor- } p=0,4448 ; \text { Lagrange } \\
\chi^{2}(1)=0,00 \text { e valor- } p= \\
1,000\end{array}$ & $\begin{array}{l}\text { Sim. } F(1,156)= \\
19630,498 \text { e } \\
\text { valor-p = } \\
0,0000\end{array}$ & $\begin{array}{l}\text { Sim. } \chi^{2}(1)=247,08 \\
\text { e valor-p }=0,0000\end{array}$ & 1,01 \\
\hline
\end{tabular}

Fonte: resultados da pesquisa.

1 - Teste Wooldridge. ${ }^{2}$ - Teste Wald para modelos de efeitos fixos e aleatórios; Teste Breusch-Pagan para modelo pooled.

3 - Teste VIF (Variance Inflation Factor).

Para os níveis normais de gerenciamento por atividades reais (equações 1,2 e 3 ) o teste Chow (valor$p$ menor que 0,05 ) indicou preferência do modelo fixo em detrimento do pooled, enquanto que o teste Hausmann (valor-p maior que 0,05 ) demonstrou que o modelo aleatório é mais adequado que o fixo apenas para FCO. Para PROD e DD o teste Hausmann (valor-p menor que 0,05 ) indicou que o método fixo é mais adequado que o aleatório (Tabela 2). Para os níveis anormais (equações 4,5 e 6 ) e REM (equações 7) os resultados dos testes Chow (valor-p maior que 0,05 ) indicaram que o modelo pooled é preferível ao fixo e 0 teste Lagrange (valor-p maior que 0,05 ) confirmou que o método pooled é preferível ao aleatório (Tabela 2). Assim, os modelos anormais e REM foram calculados através de pooled regression. 
Inicialmente apresentam-se os resultados referentes aos níveis normais de fluxo de caixa operacional (FCO), nível de produção (PROD) e de despesas discricionárias (DD). Em seguida, expõem-se os resultados relativos aos níveis anormais e a medida agregada de gerenciamento de resultados por atividades reais.

O nível normal da variável dependente fluxo de caixa operacional (FCO) foi estimado pela equação 1 (Tabela 3), originando os níveis anormais do fluxo de caixa operacional (AFCO). A única variável significante para o modelo FCO foi a variável receita líquida que apresentou valor positivo de 0,1539 em nível de $1 \%$. Esse é um resultado coerente com Reis et al. (2015), Rodrigues et al. (2017) e Roychowdury (2006), indicando que um aumento na receita líquida reflete em um aumento no Fluxo de Caixa Operacional.

Tabela 3:

Coeficientes do modelo de fluxo de caixa operacional (FCO)

\begin{tabular}{|c|c|c|c|c|}
\hline Variáveis & Coeficientes & Desvios padrão robustos dos erros & Z & Valor-p \\
\hline $1 / \mathrm{A}_{i t-1}$ & 8,0865 & 12,7228 & 0,64 & 0,525 \\
\hline $\mathrm{RL}_{i t} / \mathrm{A}_{i t-1}$ & 0,1539 & 0,3740 & 4,11 & $0,000^{*}$ \\
\hline$\Delta \mathrm{RL}_{i t} / \mathrm{A}_{i t-1}$ & $-0,2693$ & 0,1874 & $-1,44$ & 0,151 \\
\hline Intercepto & 0,1524 & 0,0346 & 0,44 & 0,660 \\
\hline $\mathrm{R}^{2}$ & & 0,6648 & & \\
\hline Prob $>\chi^{2}$ & & $0,0000^{*}$ & & \\
\hline Erros padrões robustos & & Sim & & \\
\hline Efeitos & & Aleatórios & & \\
\hline Número de observações & & 1570 & & \\
\hline
\end{tabular}

Fonte: resultados da pesquisa.

Legenda: $\quad$ *Significativo a 1\%; $\quad$ **Significativo a 5\%; $\quad{ }^{* * * S i g n i f i c a t i v o ~ a ~} 10 \%$.

$\mathrm{A}_{i t-1}$ : Total do Ativo da empresa $i$ do período $t-1 ; \mathrm{RL}_{i t}$ : Receita Líquida da empresa $i$ no período $t ; \Delta \mathrm{RL}_{i t}$ : Variação na Receita Líquida da empresa $i$ do período $t$ em relação ao $t-1$.

A variação da receita líquida teve um coeficiente negativo, o que indicaria indícios de gerenciamento de resultados por decisões operacionais, porém, não foi significativo, corroborando Reis et al. (2015) e Roychowdury (2006) que encontraram resultados similares. Portanto, uma variação positiva das vendas não implica em variação negativa do Fluxo de Caixa Operacional do período corrente. Caso essa variação da receita fosse significativa, uma possível explicação é dada por Rodrigues et al. (2017, p. 96) que "consiste na hipótese de a variação das receitas serem decorrente de um relaxamento de crédito, o que não irá refletir diretamente no Fluxo de Caixa". Para Cohen et al. (2008), isso reforçaria a ideia de que uma concessão de descontos nos preços ou condições de crédito mais facilitadas resulta em menor FCO no período corrente apesar de uma variação positiva das vendas.

A Tabela 4 especifica os níveis normais das atividades operacionais relacionados ao nível de produção (PROD). As variáveis $R L_{i t} / A_{i t-1}, \Delta R L_{i t} / A_{i t-1}$ e $\Delta R L_{i t-1} / A_{i t-1}$ foram todas significativas a $1 \%$. $A R L_{i t} / A_{i t-1} e$ a $\Delta R L_{i t} / A_{i t-1}$ possuem relação positiva com o nível de produção, indicando que aumentos na receita implicam em aumento nos níveis de produção, alinhando-se a Reis et al. (2014), Rodrigues et al. (2017) e Roychowdury (2006). Esse resultado se apresenta conforme o esperado, já que quando as vendas aumentam a produção cresce.

Por sua vez, a variável $\Delta \mathrm{RL}_{\mathrm{it}-1} / \mathrm{A}_{\mathrm{it}-1}$ (Tabela 4) possui relação negativa com a produção em acordo com Roychowdury (2006) e Zang (2012), o que apresenta indícios de que as empresas utilizam decisões relacionadas ao volume de produção para aumentar os resultados contábeis, pois quando as vendas aumentam o nível de produção diminui e o esperado era aumentar a produção para atender a demanda.

Tabela 4:

Coeficientes do modelo do nível de produção (PROD)

\begin{tabular}{|c|c|c|c|c|}
\hline Variáveis & Coeficientes & Desvios padrão robustos dos erros & z & Valor-p \\
\hline $1 / \mathrm{A}_{i t-1}$ & 22,0980 & 21,7842 & 1,01 & 0,312 \\
\hline $\mathrm{RL}_{i t} / \mathrm{A}_{i t-1}$ & 0,6824 & 0,0695 & 9,82 & $0,000^{*}$ \\
\hline$\Delta \mathrm{RL}_{i t} / \mathrm{A}_{i t-1}$ & 1,6712 & 0,2944 & 5,68 & $0,000^{*}$ \\
\hline$\Delta \mathrm{RL}_{i t-1} / \mathrm{A}_{i t-1}$ & $-0,9649$ & 0,3216 & $-3,00$ & $0,003^{*}$ \\
\hline Intercepto & $-0,0521$ & 0,0943 & $-0,55$ & 0,581 \\
\hline $\mathrm{R}^{2}$ & & 0,9740 & & \\
\hline Prob > F & & $0,0000^{*}$ & & \\
\hline Erros padrões robustos & & Sim & & \\
\hline Efeitos & & Fixos & & \\
\hline Número de observações & & 1570 & & \\
\hline
\end{tabular}

Fonte: resultados da pesquisa.

Legenda: *Significativo a $1 \%$; **Significativo a $5 \%$;

*** Significativo a $10 \%$.

$\mathrm{A}_{i t-1}$ : Total do Ativo da empresa $i$ do período $t-1 ; \mathrm{RL}_{i t:}$ Receita Líquida da empresa $i$ no período $t ; \Delta \mathrm{RL}_{i t}$ : Variação na Receita Líquida da empresa $i$ do período $t$ em relação ao $t-1 ; \Delta \mathrm{RL}_{i t-1}$ : Variação na Receita Líquida da empresa $i$ do período $t-1$ em relação ao $t-2$.

Gunny (2010) e Zang (2012) preconizam que as empresas provavelmente utilizam valores baixos de despesas discricionárias para o gerenciamento de resultados por atividades reais. A Tabela 5 apresenta os resultados dos níveis normais de despesas discricionárias (DD) e, de acordo com Roychowdhury (2006), 
quanto mais a empresa vende seus produtos, espera-se que os valores com as vendas e despesas administrativas sejam maiores.

Tabela 5:

Coeficientes do modelo de despesas discricionárias (DD)

\begin{tabular}{|c|c|c|c|c|}
\hline Variáveis & Coeficientes & Desvios padrão robustos dos erros & $\mathrm{z}$ & Valor-p \\
\hline $1 / \mathrm{A}_{i t-1}$ & 21,60 & 18,6047 & 1,16 & 0,247 \\
\hline $\mathrm{RL}_{i t-1} / \mathrm{A}_{i t-1}$ & 0,2025 & 0,0562 & 3,60 & $0,000^{*}$ \\
\hline Intercepto & $-0,0820$ & 0,0967 & $-0,85$ & 0,398 \\
\hline $\mathrm{R}^{2}$ & & 0,7867 & & \\
\hline Prob > F & & $0,0019^{*}$ & & \\
\hline Erros padrões robustos & & Sim & & \\
\hline Efeitos & & Fixos & & \\
\hline Número de observações & & 1570 & & \\
\hline
\end{tabular}

Fonte: resultados da pesquisa.

Legenda: $\quad$ *Significativo a 1\%; $\quad$ **Significativo a 5\%; $\quad{ }^{* * *}$ Significativo a $10 \%$.

$A_{i t-1}$ : Total do Ativo da empresa $i$ do período $t-1 ; L_{i t-1}$ : Receita Líquida da empresa $i$ no período $t-1$.

Em relação à regressão das despesas discricionárias (Tabela 5), o coeficiente positivo e significante a 1\% para o parâmetro envolvendo a receita é consistente com Reis et al. (2015), Rodrigues et al. (2017), Roychowdury (2006) e Zang (2012). Dessa forma, um aumento de uma unidade na receita impactará positivamente as despesas discricionárias em 0,2025. Isso significa que as despesas discricionárias acompanham o volume de vendas.

Com base na Tabela 6, verifica-se que os níveis anormais do Fluxo de Caixa Operacional (AFCO) não estão relacionados ao tamanho da empresa e com o retorno sobre o ativo mesmo resultado encontrado por Reis et al. (2015). Contrariamente a Reis et al. (2015), a variável Market-to-book não se mostrou significativa. Ao analisar o coeficiente da variável dummy, nota-se que ele foi significativo, convergindo com Reis et al. (2015), e o sinal negativo como esperado, baseado em Roychowdhury (2006). Isso evidencia que as empresas manipularam as vendas de maneira a ter um comportamento anormal do fluxo de caixa.

Portanto, as empresas que divulgaram uma margem de lucro entre 0 e $1 \%$ estão com nível anormal de fluxo de caixa menor que as demais empresas da amostra, ou seja, essas empresas podem ter concedido descontos ou condições de crédito mais favoráveis. Esse fato apresenta efeito adverso na rentabilidade futura, pois, segundo Gunny (2010), pode-se levar a margem de lucros menores nos períodos subsequentes.

$\mathrm{Na}$ Tabela 6 verifica-se que para os níveis anormais de despesas discricionárias (ADD), as variáveis tamanho, Market-to-book e retorno sobre o ativo não se mostraram significativas, diferente ao que se apresenta em Gunny (2010), Roychowdhury (2006) e Zang (2012), quando todas as variáveis foram significativas. Uma possível explicação refere-se à amostra empregada nesses estudos, que consiste em empresas americanas. Em comparação ao trabalho de Reis et al. (2015), o índice Market-to-book se apresenta congruente, ou seja, não foi significativo. Já as variáveis tamanho e retorno sobre o ativo são contrárias, sendo significativas no estudo citado. Quando verificado o valor da variável dummy, nota-se que a mesma é negativa e significativa, convergindo com os estudos de Gunny (2010), Reis et al. (2015), Roychowdhury (2006) e Zang (2012). Assim, as evidências estatísticas indicam que as empresas suspeitas, que divulgaram uma margem de lucro entre 0 e $1 \%$, reduziram as despesas discricionárias de maneira anormal a fim de gerenciar o resultado das atividades reais.

Tabela 6:

Coeficientes das equações AFCO, ADD, APROD e REM

\begin{tabular}{|c|c|c|c|c|}
\hline Variáveis & AFCO & ADD & APROD & REM \\
\hline Intercepto & $0,2323^{*}$ & $0,3656^{\star *}$ & 0,2267 & $-0,3721$ \\
\hline $\mathrm{D}_{i t}$ & $-0,0932^{*}$ & $-0,1439^{* *}$ & $-0,5671^{*}$ & $-0,3300^{*}$ \\
\hline $\mathrm{TAM}_{i t}$ & $-0,0014$ & $-0,0157$ & 0,0978 & $0,1149^{\star \star}$ \\
\hline $\mathrm{MTB}_{i t}$ & 0,0007 & 0,0018 & 0,0030 & 0,0005 \\
\hline $\mathrm{ROA}_{i t}$ & 0,0127 & 0,0136 & 0,0715 & 0,0453 \\
\hline Valor-p & $0,0679^{\star * *}$ & $0,0510^{\star \star *}$ & $0,0376^{\star *}$ & $0,0307^{* *}$ \\
\hline $\mathrm{R}^{2}$ & 0,0001 & 0,0004 & 0,0009 & 0,0033 \\
\hline Número de observações & 1570 & 1570 & 1570 & 1570 \\
\hline
\end{tabular}

Fonte: resultados da pesquisa.

Legenda: "Significativo a $1 \% ;{ }^{* *}$ Significativo a $5 \%$; $\quad * * *$ Significativo a $10 \%$.

AFCO $_{i t}$ : Nível anormal de FCO da empresa $i$ no período $t$ (equação 5); APROD it: Nível anormal de PROD da empresa $i$ no período $t$ (equação 6); ADD $_{i t}$ : Nível anormal de DD da empresa $i$ no período $t$ (equação 7); REMit: Medida agregada (equação 9 ) da empresa $i$ no período $t$; $D_{i t}$ : Dummy que assume valor 1 para as empresas suspeitas e 0 , caso contrário, da empresa $i$ do período $t$; TAM $i t$ : Logaritmo natural do total dos ativos da empresa $i$ no período $t$; MTB $_{i t}$ : $O$ valor de mercado do capital dividido pelo patrimônio líquido da empresa $i$ no período $t$; $\mathrm{ROA}_{i t}$ : Retorno sobre o ativo da empresa $i$ do período $t$.

Ainda em relação à Tabela 6 , constata-se que dentre os coeficientes relacionados aos níveis anormais de produção (APROD), as variáveis de controle tamanho, market-to-book e retorno sobre o ativo não se mostraram significativas, estando em conformidade com Reis et al. (2015). Por outro lado, a variável de 
interesse (dummy) mostrou-se significativa. Esse resultado indica o gerenciamento de resultados por meio de relatórios contábeis, utilizando a estratégia de aumento dos níveis de produção, e está alinhado com Gunny (2010), Roychowdhury (2006) e Zang (2012).

Desse modo, para gerenciar os resultados operacionais se fez necessário ter a possibilidade de produzir mais, aproveitando os ganhos de escala e, posteriormente, ajustando o estoque. Esse resultado converge para o argumento de Scott (2012) em que grandes empresas têm maiores conflitos de agência porque apresentam uma elevada escala de operação, que proporciona oportunidades e incentivos para os gestores desviarem-se dos objetivos do principal conforme a Teoria da Agência.

Esses resultados indicam que as três proxies de gerenciamento de resultados por decisões operacionais são empregadas pelas empresas brasileiras para evitar reportar prejuízos, ampliando os achados de estudos nacionais (Reis et al., 2014; Reis et al., 2015; Rodrigues et al., 2017).

No que concerne à medida agregada REM (Tabela 6), pode-se concluir que as empresas que apresentaram margem de lucro entre 0 e $1 \%$ incorreram no gerenciamento de atividades operacionais de forma anormal, visto que a variável dummy apresentou-se negativa e significativa, ou seja, a hipótese 1 não é rejeitada. Esse resultado está de acordo com os encontrados por Cupertino et al. (2016), Gunny (2010), Reis et al. (2015) e Roychowdhury (2006). Destaca-se que a prática de gerenciamento de resultados operacionais das empresas da amostra se concentra em baixos níveis anormais de fluxo de caixa, de despesas discricionárias e elevados custos de produção, ou seja, em conformidade ao que prediz Cohen et al. (2008): é provável que as empresas que gerenciam os lucros para cima tenham uma combinação de fluxo de caixa excepcionalmente baixo das operações, e/ou despesas discricionárias baixas e/ou custos de produção excepcionalmente altos.

Por fim, com base na Tabela 6, destaca-se que o gerenciamento de resultados por atividades reais está diretamente associado ao tamanho da empresa conforme Cupertino et al. (2017) e Gunny (2010). Duas possíveis explicações são a capacidade das grandes empresas de produzir mais, em algum momento, para aumentar o estoque (Reis et al., 2015) e o custo político que podem levar as empresas a gerenciar os resultados, visto que estão sob maior escrutínio público e dos órgãos de regulação (Scott, 2012; Silva, Zonatto, Dal Magro, \& Klann, 2019). As demais variáveis de controle (MTB e ROA) não foram significativas conforme os resultados encontrados por Reis et al. (2015). Já o trabalho de Cupertino et al. (2016) encontrou uma relação negativa e significativa entre REM e ROA.

Conclui-se que os possíveis mecanismos de mitigação dos problemas de agência não são suficientes para evitar o gerenciamento de resultados. Portanto, os gestores têm incentivos ao gerenciar os resultados e não apresentar prejuízos em seus relatórios contábeis, uma vez que os usuários da informação contábil poderiam reagir negativamente a essas informações. Nesse sentido, Silva et al. (2019, p. 192) pontuam que "o gerenciamento de resultados ocorre conforme os objetivos dos gestores, os quais são munidos pelo comportamento oportunista, tanto pessoal quanto ligado aos objetivos organizacionais".

\section{Considerações Finais}

Pesquisas sugerem que o gerenciamento de resultados é determinado pelas escolhas da administração visando benefícios específicos. Assim, o presente estudo teve como objetivo verificar se as empresas brasileiras listadas na Brasil, Bolsa, Balcão $[B]^{3}$ evitaram reportar prejuízos baseado no gerenciamento de resultados por atividades operacionais.

Os resultados certificaram que as empresas que tiveram margem de lucro positiva entre 0 e $1 \%$ fizeram uso do gerenciamento de resultados operacional para evitar incorrer em divulgação de prejuízos nos relatórios. Os resultados têm implicações para as partes interessadas externas, incluindo investidores, analistas financeiros e governo, que devem levar em consideração os incentivos gerenciais ao avaliar o desempenho das empresas.

A pesquisa se diferencia dos trabalhos de Reis et al. (2014) e Reis et al. (2015), já que os referidos estudos fornecem evidências de que as empresas se utilizam apenas das despesas com vendas, gerais e administrativas para evitarem reportar prejuízo, enquanto que, os resultados desta pesquisa apontam que 0 fluxo de caixa operacional, as despesas discricionárias e o nível de produção são empregados pelas empresas com essa finalidade. Esse resultado se coaduna aos achados de Roychowdhury (2006) e, portanto, com a literatura internacional.

Todavia, os achados estão sujeitos a certas ressalvas. As associações estatísticas não representam necessariamente causalidade e não se podem descartar explicações alternativas, embora tenham sido adotadas as proxies de pesquisa estabelecidas anteriormente. Nesse sentido, os resultados devem ser interpretados com cautelas, visto que a receita é influenciada por mudanças nos preços, bem como por outros fatores e não apenas por decisões dos gestores. Ademais, os resultados não são necessariamente generalizáveis para qualquer tipo de empresa, uma vez que os achados dizem respeito a empresas de capital aberto. Posto isso, amostras de tamanho e características distintas podem apresentar resultados divergentes.

Sugere-se, como pesquisas futuras, que essa análise seja realizada com base nos relatórios trimestrais, visto que os resultados trimestrais também são relevantes para o mercado e os investidores. 


\section{Referências}

Almeida-Santos, P. S., Verhagem, J. A., \& Bezerra, F. A. (2011). Gerenciamento de resultados contábeis por meio de decisões operacionais e a governança corporativa: análise nas indústrias siderúrgicas e metalúrgicas. Revista de Contabilidade e Organizações, 5(13), 55-74.

https://doi.org/10.11606/rco.v5i13.34804

Banker, R. D, Byzalov, D., \& Plehn-Dujowich, J. M. (2014). Demand uncertainty and cost behavior. The Accounting Review, 89(3), 839-865. https://doi.org/10.2308/accr-50661

Barton, J. (2001).Does the use of financial derivatives affect earnings management decisions? The Accounting Review, 76(1), 1-26. https://doi.org/10.2308/accr.2001.76.1.1

Burgstahler, D., \& Dichev, I. (1997). Earnings management to avoid losses and earnings decreases. Journal of Accounting and Economics, 24(1), 99-126. https://doi.org/10.1016/S0165-4101(97)00017-7

Cohen, D., Dey, A., \& Lys, T. (2008). Real and accrual-based earnings management in the pre-and postSarbanes-Oxley periods. The Accounting Review, 83(3), 757-787. https://doi.org/10.2308/accr.2008.83.3.757

Cohen, D. A., \& Zarowin, P. (2010). Accrual-based and real earnings management activities around seasoned equity offerings. Journal of Accounting and Economics, 50, 2-19. https://doi.org/10.1016/i.jacceco.2010.01.002

Cupertino, C. M., Martinez, A. L., \& Costa Jr., N. C. A. (2016). Consequências para a rentabilidade futura com o gerenciamento de resultados por meio de atividades operacionais reais. Revista Contabilidade \& Finanças, 27(71), 232-242. https://doi.org/10.1590/1808-057×201602520

Cupertino, C. M., Martinez, A. L., \& Costa Jr., N. C. A. (2017). Earnings management strategies in Brazil: Determinant costs and temporal sequence. Contaduría y Administración, 62(5), 1460-1478. https://doi.org/10.1016/j.cya.2016.11.002

Dal Magro, C. B., Lavarda, C. E. F., \& Klann, R. C. (2019). Abordagens de estudos sobre gerenciamento de resultados: novas perspectivas a partir da análise bibliométrica. Revista Mineira de Contabilidade, 20(1), 3449. https://doi.org/10.21714/2446-9114RMC2019v20n1t03

Dani, A. C., Dal Magro, C. B., \& Klann, R. C. (2017). Earnings management through real activities: review of the existing literature and suggestions for future investigations. Revista de Gestão, Finanças $e$ Contabilidade, 7(2), 102-120. http://dx.doi.org/10.29386/rgfc.v7i2.2791

Defond, M. L., \& Jiambalvo, J. (1994). Debt covenant violation and manipulation of accruals. Journal of Accounting and Economics, 17(1-2), 145-176. https://doi.org/10.1016/0165-4101(94)90008-6

Dichev, I. D., Graham, J. R., Harvey, C. R., \& Rajgopal, S. (2013). Earnings quality: evidence from the field. Journal of Accounting and Economics, 56, 1-33. https://doi.org/10.1016/j.jacceco.2013.05.004

Dierynck, B., Landsman, W. R., \& Renders, A. (2012). Do managerial incentives drive cost behavior? evidence about the role of the zero earnings benchmark for labor cost behavior in Belgian private firms. The Accounting Review, 87(4), 1219-1246. https://doi.org/10.2308/accr-50153

Francis, F., Lafond, R., Olsson, P., \& Schipper, K. (2005). The market pricing of accruals quality. Journal of Accounting and Economics, 39(2), 295-327, https://doi.org/10.1016/j.jacceco.2004.06.003

Francis, B., Hasan, I., \& Li, L. (2016). Abnormal real operations, real earnings management, and subsequent crashes in stock prices. Review of Quantitative Finance and Accounting, 46(2), 217-260. https://doi.org/10.1007/s11156-014-0468-y

Ge, W., \& Kim, J. (2014). Real earnings management and the cost of new corporate bonds. Journal of Business Research, 67(4), 641-647. https://doi.org/10.1016/j.jbusres.2013.01.021

Graham, J. R., Harvey, C. R., \& Rajgopal, S. (2005). The economic implications of corporate financial reporting. Journal of Accounting and Economics, 40, 3-73. https://doi.org/10.1016/j.jacceco.2005.01.002 
Gujarati, D. N., \& Porter, D. C. (2011). Econometria básica. Porto Alegre: AMGH.

Gunny, K. A. (2010). The relation between earnings management using real activities manipulation and future performance: evidence from meeting earnings benchmarks. Contemporary Accounting Research, 27, 855-888. https://doi.org/10.1111/j.1911-3846.2010.01029.x

Han, S., Rezaee, Z.; \& Tuo, L. (2019). Is cost stickiness associated with management earnings forecasts? Asian Review of Accounting, ahead-of-print. https://doi.org/10.1108/ARA-04-2018-0096

Healy, P. M., \& WAHLEN, J. M. (1999). A review of the earnings management literature and its implications for standard setting. Accounting Horizons, 13(4), 365-383, 1999. https://doi.org/10.2308/acch.1999.13.4.365

Johnson, E. S. (2016). Do changes in the SG\&A ratio provide different information about changes in future earnings, analyst forecast revisions, and stock returns under different circumstances? Advances in Accounting, 34, 90-98. https://doi.org/10.1016/i.adiac.2016.07.010

Kim, J. B., \& Sohn, B. C. (2013). Real earnings management and cost of capital. Journal of Accounting and Public Policy, 32(6), 518-543, 2013. https://doi.org/10.1016/j.jaccpubpol.2013.08.002

Kothari, S. P., Mizik, N., \& Roychowdhury, S. (2016). Managing for the moment: The role of earnings management via real activities versus accruals in SEO valuation. The Accounting Review, 91(2), 559-586. https://doi.org/10.2308/accr-51153

Lo, K. (2008). Earnings management and earnings quality. Journal of Accounting and Economics, 45, 350357. https://doi.org/10.1016/.j.jacceco.2007.08.002

Man, C. K., \& Wong, B. (2013). Corporate governance and earnings management: A survey of literature. Journal of Applied Business Research, 29(2), 391-418. https://doi.org/10.19030/jabr.v29i2.7646

Martinez, A. L. (2001). Gerenciamento dos resultados contábeis: estudo empírico das companhias abertas brasileiras. (Tese de doutorado). Retrieved from https:/teses.usp.br/teses/disponiveis/12/12136/tde-14052002-110538/publico/tde.pdf

Martinez, A. L. (2008). Detectando earnings management no Brasil: estimando os accruals discricionários. Revista de Contabilidade \& Finanças, 19(46), 7-17. https://doi.org/10.1590/S1519-70772008000100002

Martinez, A. L. (2013). Earnings management in Brazil: a survey of the literature. Brazilian Business Review, 10(4), 1-31. https://doi.org/10.15728/bbr.2013.10.4.1

Martinez, A. L., \& Cardoso, R. L. (2009). Gerenciamento da informação contábil no Brasil mediante decisões operacionais. REAd: Revista Eletrônica de Administração, 15(3), 1-27.

Paredes, A. A. P., \& Wheatley, C. (2017). Real earnings management or "just business". Journal of Financial Economic Policy, 9(3). https://doi.org/10.1108/JFEP-09-2016-0065

Paulo, E. (2007). Manipulação das informações contábeis: uma análise teórica e empírica sobre os modelos operacionais de detecção de gerenciamento de resultados. (Tese de doutorado). Retrieved from https://10.11606/T.12.2007.tde-28012008-113439

Paulo, E., \& Mota, R. H. G. (2019). Ciclos econômicos e estratégias de gerenciamento de resultados contábeis: um estudo nas companhias abertas brasileiras. Revista Contabilidade \& Finanças, 30(80), 216233. https://doi.org/10.1590/1808-057×201806870

Reis, E. M., Cunha, J. V. A., \& Ribeiro, D. M. (2014). Análise do gerenciamento de resultados por meio de decisões operacionais nas empresas componentes do IBrX - índice Brasil. Advances in Scientific and Applied Accounting, 7(2), 201-203. https://doi.org/10.14392/ASAA.2014070202

Reis, E. M., Lamounier, W. M, \& Bressan, V. G. F. (2015). Evitar divulgar perdas: um estudo empírico do gerenciamento de resultados por meio de decisões operacionais. Revista Contabilidade \& Finanças, 26(69), 247-260. http://dx.doi.org/10.1590/1808-057x201501070 
Rodrigues, R. M. R. C., Paulo, E., \& Melo, C. L. L. de. (2017). Gerenciamento de resultados por decisões operacionais para sustentar desempenho nas empresas não-financeiras do Ibovespa. Revista Contabilidade Vista \& Revista, 28(3), 82-102.

Rodrigues, R. M. R. C., Melo, C. L. L. de, \& Paulo, E. (2019). Gerenciamento de resultados e nível dos accruals discricionários trimestrais no mercado acionário brasileiro. Brazilian Business Review, 16(3), 297314. http://dx.doi.org/10.15728/bbr.2019.16.3.6

Roychowdhury, S. (2006). Earnings management through real activities manipulation. Journal of Accounting and Economics, 42(3), 335-370.

https://doi.org/10.1016/i.jacceco.2006.01.002

Scott, W. R. (2012). Financial Accounting Theory. Toronto: Pearson, 2012.

Silva, P. Y. C. da, \& Fonseca, M. W. da. (2015). Gerenciamento de resultados: estudo empírico em empresas brasileiras e portuguesas antes e após a adoção das IFRS. BASE: Revista de Administração e Contabilidade da Unisinos, 12(3), 193-209. https://doi.org/10.4013/base.2015.123.03

Silva, A., Zonatto, V. C. S., Dal Magro, C. B., \& Klann, R. C. (2019). Comportamento assimétrico dos custos e gerenciamento de resultados. Brazilian Business Review, 16(2), 191-206.

http://dx.doi.org/10.15728/bbr.2019.16.2.6

Sincerre, B. P., Sampaio, J. O., Famá, R., \& Santos, J. A. (2016). Emissão de dívida e gerenciamento de resultados. Revista Contabilidade \& Finanças, 27(72), 291-305. https://doi.org/10.1590/1808-

$\underline{057 \times 201601660}$

Skinner, D. J., \& Sloan, R.G. (2002). Earnings surprises, growth expectations and stock returns or don't let an earnings torpedo sink your portfolio. Review of Accounting Studies, 7, 289-312.

https://doi.org/10.1023/A:1020294523516

Vladu, A. B., \& Cuzdriorean, D. D. (2014). Detecting earnings management: insights from the last decade leading journals published research. Procedia Economics and Finance, 15, 695- 703.

https://doi.org/10.1016/S2212-5671(14)00542-5

Zang, A. Y. (2012). Evidence on the trade-off between real activities manipulation and accrual-based earnings management. The Accounting Review, 87(2), 675-703. https://doi.org/10.2308/accr-10196

\title{
NOTAS
}

AGRADECIMENTOS

Os autores agradecem ao editor e aos avaliadores anônimos pelos comentários e sugestões relevantes.

\section{CONTRIBUIÇÃO DE AUTORIA}

Concepção e elaboração do manuscrito: N. A. Pereira; M. Tavares.

Coleta de dados: N. A. Pereira

Análise de dados: N. A. Pereira; M. Tavares.

Discussão dos resultados: N. A. Pereira; M. Tavares.

Revisão e aprovação: N. A. Pereira; M. Tavares.

CONJUNTO DE DADOS DE PESQUISA

O conjunto de dados que dá suporte aos resultados deste estudo não está disponível publicamente.

\section{FINANCIAMENTO}

Não se aplica.

\section{CONSENTIMENTO DE USO DE IMAGEM}

Não se aplica.

\author{
APROVAÇÃO DE COMITÊ DE ÉTICA EM PESQUISA \\ Não se aplica.
}

\section{CONFLITO DE INTERESSES}

Não se aplica. 


\section{LICENÇA DE USO}

Os Direitos Autorais para artigos publicados neste periódico são do autor, com direitos de primeira publicação para a Revista. Em virtude de aparecerem nesta Revista de acesso público, os artigos são de uso gratuito, com atribuições próprias, em aplicações educacionais, de exercício profissional e para gestão pública. A Revista adotou a licença Creative Commons Atribuição 4.0 Internacional - CC BY NC ND. Esta licença permite acessar, baixar (download), copiar, imprimir, compartilhar, reutilizar e distribuir os artigos desde que com a citação da fonte, atribuindo os devidos créditos de autoria. Nesses casos, nenhuma permissão é necessária por parte dos autores ou dos editores. Autores têm autorização para assumir contratos adicionais separadamente, para distribuição não-exclusiva da versão do trabalho publicada nesta revista (ex.: publicar em repositório institucional ou um capítulo de livro).

\section{PUBLISHER}

Universidade Federal de Santa Catarina. Curso de Ciências Contábeis e Programa de Pós-graduação em Contabilidade. Publicação no Portal de Periódicos UFSC. As ideias expressadas neste artigo são de responsabilidade de seus autores, não representando, necessariamente, a opinião dos editores ou da universidade.

\section{EDITORES}

Carlos Eduardo Facin Lavarda e Suliani Rover

\section{HISTÓRICO}

Recebido em: 21/01/2020 - Revisado por pares em: 04/06/2020 - Reformulado em: 09/06/2020 Recomendado para publicação em: 15/10/2020 - Publicado em: 15/01/2021 